\title{
Da cidade lúdica aos Domingos da Criação: a constelação Frederico Morais
}

\author{
From the Playful City to the Sundays of Creation: \\ the Frederico Morais Constellation
}

\section{De la ciudad lúdica a los Domingos de la Creación: la constelación Frederico Morais}

$\frac{\text { André Leal }^{*}}{\text { http://dx.doi.org/10.22409/poiesis.2033.413-434 }}$

\begin{abstract}
RESUMO: O presente artigo analisa a trajetória do crítico Frederico Morais à luz de seu envolvimento com questões artísticas, sociais e políticas do período que culmina com a realização dos Domingos da Criação no MAM-RJ em 1971. Pretendemos demonstrar sua afinidade com questões que lhe eram contemporâneas na abordagem da participação do público na constituição da obra de arte e em sua transformação por parte de artistas e curadores em uma experiência aberta. Do mesmo modo, sua atuação abre o museu para o Aterro, concretizando o projeto de Affonso Eduardo Reidy. Entre as proposições de Hélio Oiticica, a ideia de Crelazer é um ponto fundamental para compreendermos a trajetória de Morais.
\end{abstract}

PALAVRAS-CHAVE: Frederico Morais; Crelazer; situacionismo; arte contemporânea

"André Leal é doutorando do PPGAV-EBA-UFRJ, na linha Linguagens Visuais. É bolsista do PROEX-Capes.

E-mail: coxaleal@gmail.com. Orcid: http://orcid.org/0000-0002-0021-6616 
ABSTRACT: This article analyzes the trajectory of the art critic Frederico Morais in the light of his involvement with artistic, social and political issues during the period that culminated with the Sundays of Creation at MAM-RJ in 1971. We intend to demonstrate his affinity with contemporary issues such as the approach to public participation in the constitution of the work of art and its transformation by artists and curators into an open experience. In the same way, his performance opens the museum to the Aterro, materializing the project of Affonso Eduardo Reidy. Among the propositions of Hélio Oiticica, the idea of Crelazer is a fundamental point to understand the trajectory of Morais.

KEYWORDS: Frederico Morais; Crelazer; situationism; contemporary art

RESUMEN: El presente artículo analiza la trayectoria del crítico Federico Morales a la luz de su implicación con cuestiones artísticas, sociales y políticas del período que culmina con la realización de los Domingos de la Creación en el MAM-RJ, en 1971. Pretendemos demostrar su afinidad con cuestiones que le eran contemporáneas en el abordaje de la participación del público en la constitución de la obra de arte y en su transformación por parte de artistas y curadores en una experiencia abierta. De la misma manera su actuación abre el museo para el Aterro, concretando el proyecto de Affonso Eduardo Reidy. Entre las proposiciones de Hélio Oiticica, la idea de Crelazer es un punto fundamental para comprender la trayectoria de Morais.

PALABRAS CLAVE: Frederico Morais; Crelazer; situacionismo; arte contemporáneo

Recebido: 15/4/2019; Aprovado: 19/5/2019

Como citar: LEAL, André. Da cidade lúdica aos Domingos da Criação: a constelação Frederico Morais. Poiésis, Niterói, v. 20, n. 33, p. 413-434, jan./jun. 2019.

doi: http://dx.doi.org/10.22409/poiesis.2033.413-434

Poiésis, Niterói, v. 20, n. 33, jan./jun. 2019. 


\section{Da cidade lúdica aos Domingos da Criação: a constelação Frederico Morais}

Introdução: a cidade lúdica invade o Museu de Arte Moderna

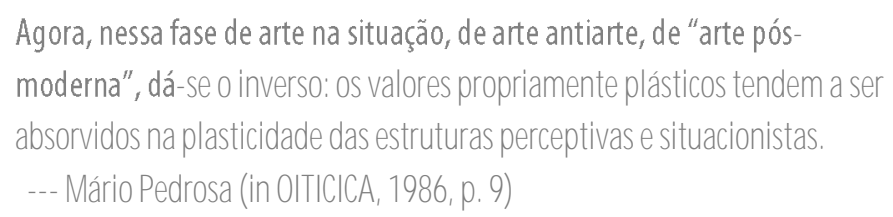

Agora, nessa fase de arte na situação, de arte antiarte, de "arte pósmoderna", dá-se o inverso: os valores propriamente plásticos tendem a ser absorvidos na plasticidade das estruturas perceptivas e situacionistas. --- Mário Pedrosa (in OITICCA, 1986, p. 9)

Em novembro de 1969, o crítico e curador Frederico Morais apresentou no IV Colóquio da Associação Brasileira de Museus de Arte a comunicação Plano-piloto para a futura cidade lúdica, na qual traça o programa do que deveria ser, para ele, um Museu de Arte PósModerna. Segundo Morais, dadas as novas condições participativas das obras de arte contemporâneas, o museu deveria ter um caráter de programador de "atividades lúdicas no vasto salão da cidade". (MORAIS in GOGAN, 2017, p. 271) Para tanto, prescindiria de acervos e salas expositivas e sua arquitetura seria a mínima necessária para abrigar as experiências propostas pelos artistas e pelo museu para participação do público. 
A "transmissão de experiências", que seria o papel do artista "pós-moderno", serviria também para desencadear no "ex-espectador" (ou participador, como insistia Hélio Oiticica), processos criativos que o descondicionariam das amarras impostas pelos diversos controles aos quais estamos sujeitos na sociedade. Para Morais, "todas as pessoas são inatamente criativas [...] e só não exercem seu potencial criador se são impedidas a isso por algum tipo de repressão - familiar, educativa, política etc." (in GOGAN, 2017, p. 242), e o museu na pós-modernidade deveria ter o caráter de liberar esse potencial em seus frequentadores. Ademais, as obras de arte pós-modernas tampouco seriam objetos acabados para serem pendurados em paredes, mas processos abertos à participação do público, que seria também cocriador das obras. (in GOGAN, 2017, p. 270)

Esse breve resumo do pensamento de Morais traz à tona uma série de questões muito caras à produção artística da virada da década de 1960 para a de 1970 e inclusive, podemos dizer, que ele colocava em prática muitas das teorias que Hélio Oiticica estava elaborando em torno de sua própria produção artística, principalmente com seu conceito de Crelazer. O artista não chega a uma definição precisa do que entende por Crelazer, posto que não era sua intenção, mas escreveu e comentou muito a esse respeito. Além disso, o conceito foi desenvolvido na prática em trabalhos como seus Parangolés e sua "produção ambiental", elaborados ao longo da segunda metade da década de 1960. Para Oiticica, trata-se também de uma questão relativa à transformação do comportamento, o crebehaviour, que incitaria "atos de vida que brotem como necessidades, como 'germes', a partir de uma situação de conflito de comportamento (comportamento condicionado e comportamento descondicionado)". (BRAGA, 2013, p. 174) Em um momento no qual mais se aproxima de uma definição do termo Crelazer, o artista afirma que ele seria:

não ocupar um lugar específico, no espaço ou no tempo, assim como viver o prazer ou não saber a hora da preguiça, é e pode ser a atividade a que se entregue um "criador". [...] 0 Crelazer é o criar do lazer ou crer no lazer? - não sei, talvez os dois, talvez nenhum. (OITICICA, 1986, p. 113)

Poiésis, Niterói, v. 20, n. 33, jan./jun. 2019. 
Não é à toa, portanto, que a produção de Oiticica esteve sempre presente nos eventos promovidos por Morais, tanto no Rio de Janeiro quanto em Belo Horizonte, como veremos adiante.

Ao mesmo tempo, o ápice dessa visão de Morais acerca da produção e da fruição artística se deu com os eventos "pedagógicos" experimentais conhecidos como Domingos da Criação, realizados ao longo de seis domingos de 1971, que se utilizaram da estrutura do Umseu de Arte Moderna do Rio de Janeiro (MAM-RJ) para promover manifestações de libertação criativa no sentido esboçado acima. Os Domingos foram, portanto, uma maneira de colocar em prática o pensamento de Morais em relação ao museu de arte pós-moderna. É curioso, porém, que o local que abrigou tais experiências tenha sido justamente o Museu de Arte Moderna que, para o crítico, foi projetado "para o futuro", resistindo "à aceleração do processo artístico atual" e cujo pátio é um "espaço expressivo e belo, [que] tem servido à realização de atividades e manifestações". (MORAIS in GOGAN, 2017, p. 277)

Vislumbramos aqui um arco temporal que reúne o modernismo arquitetônico à visão de arte pós-moderna que Morais tinha, próxima à de Mario Pedrosa, conforme definida na epígrafe deste texto. Se o edifício da FAU-USP de Vilanova Artigas, por exemplo, com seus amplos salões, serve para "amparar a imprevisibilidade da vida", como afirma Paulo Mendes da Rocha (2009, p. 27), o que dizer então da ampla marquise do MAM-RJ que cumpre ainda o papel de unir o Aterro às salas de exposição do museu? Neste sentido, não houve nenhum evento mais imprevisível que as manifestações ocorridas nos seis domingos que Morais programou e que reuniram milhares de frequentadores, iniciados ou não nas linguagens artísticas.

Efetivando a proposta de Affonso Eduardo Reidy de que o Aterro do Flamengo fosse uma extensão do MAM-RJ e vice-versa, Morais, como diretor dos programas educativos do museu, fez com que o Aterro adentrasse os espaços expositivos de diversas maneiras, como nos cursos livres da Unidade Experimental e nas exposições de fim de curso dos professores Anna Bella Geiger ou Luiz Alphonsus, por exemplo. Deste modo, a arquitetura de Reidy, ao abrir o espaço expositivo à paisagem do Aterro, trazia a natureza para dentro do museu, 


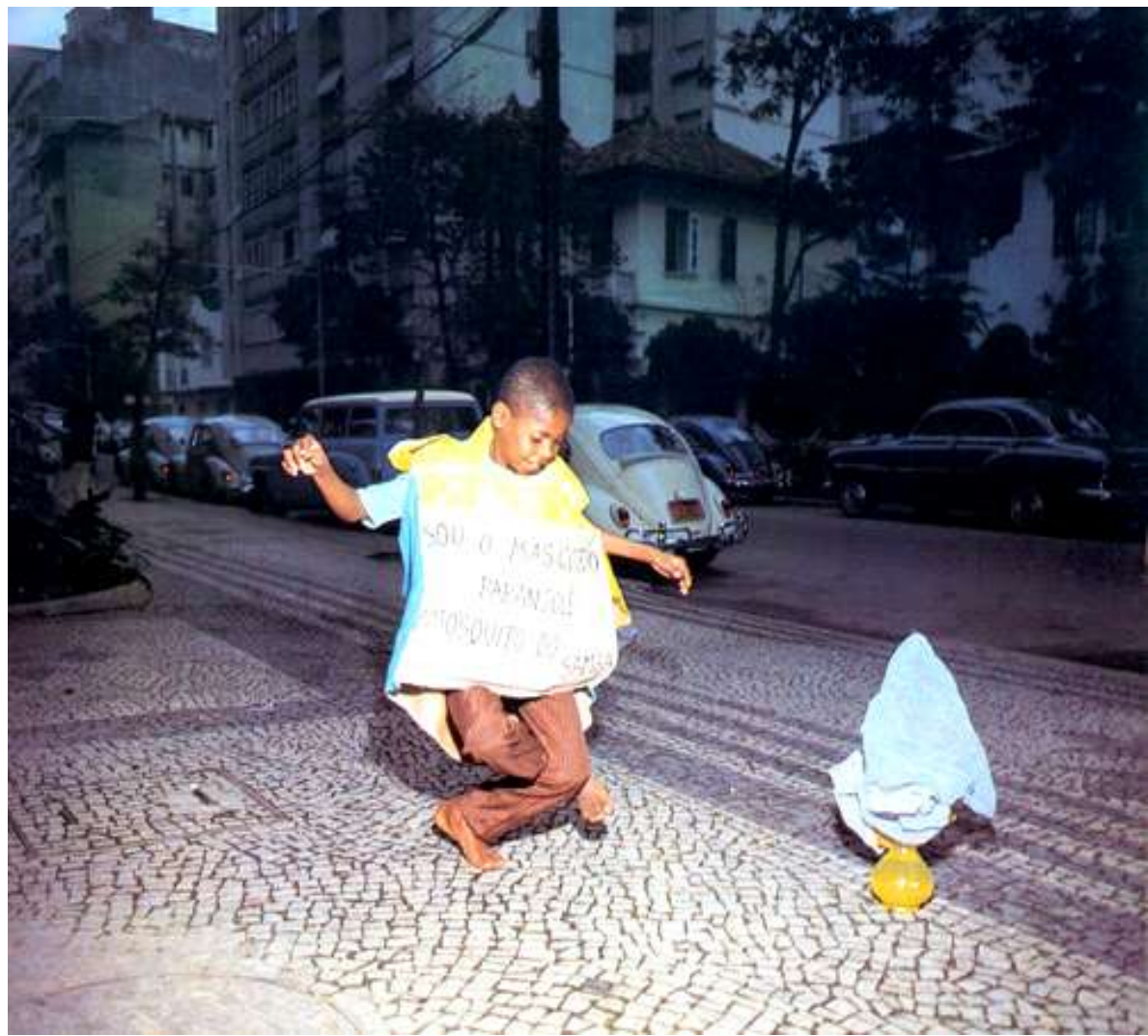

Fig. 1 - Hélio Oiticica

Mosquito da Mangueira veste Parangolé P10, capa 6 (1965) e Bólide vidro 5 (1965).

(Fonte: FAVARETTO, Celso Fernando. A invenção de Hélio Oiticica. São Paulo: EDUSP, 1992,

p. 108)

Poiésis, Niterói, v. 20, n. 33, jan./jun. 2019. 
colocando-o em relação com a onipresente paisagem carioca. Segundo Morais, "nele, paisagem e museu se complementam, a paisagem externa penetra no interior do museu, descansando o espectador após a contemplação lenta dos quadros". (in GOGAN, 2017, p. 277) Seus amplos salões também poderiam prescindir de qualquer acervo permanente e poderiam ser configurados como o verdadeiro laboratório de criatividade que pretendia Morais, uma radicalidade que, no entanto, jamais foi colocada em prática. Como afirma Jessica Gogan (2017, p. 251),

\section{a nova instituição foi concebida como um campus horizontal de "blocos" [...] em meio a jardins tropicais projetados por Roberto Burle Marx. 0 arquiteto viu seu projeto tanto como transformação do "antigo conceito de museu" quanto como criação de novas formas arquitetônicas, em que o "espaço fluente" vem substituir o "espaço confinado".}

Apesar da tensão existente entre o experimental e formas artísticas mais convencionais, a própria organização institucional do MAM-RJ cumpriu um papel efetivo na consolidação do experimentalismo nos termos propostos por Morais. Novamente de acordo com Gogan, a diretora da instituição na época, Niomar Moniz Sodré ${ }^{1}$ entendia "o museu e a arte como agentes democráticos" e elementos "fundamentais para posicionar o Brasil para o futuro". (2017, p. 252) O MAM-RJ teria funcionado, portanto, como um efetivo "gerador institucional da modernidade, reconfigurando a equação museu=memória [...]. Não se trata mais de um museu como um lugar onde a memória está alojada, mas sim produzida". (GOGAN, (2017, p. 252) Uma visão bastante próxima à que Morais levaria ao MAM-RJ e que anunciava também a possibilidade de romper as barreiras entre interior e exterior do museu, abrindo-o para experiências menos elitistas e mais democráticas. Tensões estas que são "tanto geradoras quanto desafiantes que permeiam a genealogia do experimental de uma potência de 'museu-liberdade' no MAM". (GOGAN, 2017, p. 251)

É digno de nota a estreita sintonia que Frederico Morais tinha com a produção artística da época, devido ao contato e solidariedade que mantinha com os artistas, e parte de seu entendimento da atuação do crítico de arte. Para ele, o crítico deveria "se deixar envolver pela obra", tornando-se assim "um parceiro do artista, ou um comparsa, à medida que 
Ihe acrescenta novos significados". (MORAIS, 1975, p. 52) Ao se envolver na obra e na produção do artista, o crítico também vai se tornando "um criador, um artista", pois se envolve na rede de significações - sempre novas - que a obra apresenta. (MORAIS, 1975, p. 52) Esse é um dos fundamentos de sua concepção de "nova crítica", apresentada em museus e galerias em 1969 e impulsionada por meio de exposições e programas pedagógicos que promoveu no período.

Mas a sensibilidade de Morais extrapolou o campo da produção artística, abrangendo a realidade social de modo geral, seja em questões políticas e sociais, seja no campo da arquitetura e do urbanismo, como vimos acima. Sua proposta de impulsionar a criatividade inata de cada pessoa também estava em sintonia com os eventos de maio de 1968 em Paris e no mundo. Segundo Morais, citando o sociólogo Alfred Willener, os eventos de Paris seriam "o encontro de si mesmo na coletividade, a liberação de potencialidades individuais sob uma forma coletiva sugerindo, portanto, um comportamento social e político novo, isto é, criativo". (MORAIS, 1975, p. 53) Também seria necessário um "encorajamento recíproco" para promover o "reencontro de si e o desenvolvimento das faculdades de imaginação e invenção". (MORAIS, 1975, p. 53) Se maio de 1968 representou essa liberação espontânea da criatividade inata, foi também prontamente capturado pelos poderes estabelecidos e convertido em mercadoria na roda de consumo de personalidades do neoliberalismo, como nos lembra Fredric Jameson (2015).

Um ponto de contato fundamental presente nesta visão da criatividade no maio de 1968 apresentada por Morais é com os situacionistas, grupo de pensadores, artistas e ativistas reunidos em torno da figura de Guy Debord na década de 1950, que teve papel intelectual fundamental nos eventos de Paris. O plano-piloto para a futura cidade lúdica nos remete diretamente às teorias do "urbanismo unitário" formuladas pelo grupo. Para além das teorias acerca da "sociedade do espetáculo" de Debord, trabalhadas tanto por Morais quanto por Oiticica - este, um leitor atento do ativista francês -, a ideia de um Crelazer na cidade também comparece nas formulações situacionistas. O "urbanismo unitário" teria "como objetivo formar um ambiente humano unitário no qual separações como trabalho/lazer ou público/privado serão finalmente dissolvidas" (DEBORD apud SADLER, 1998,

Poiésis, Niterói, v. 20, n. 33, jan./jun. 2019. 


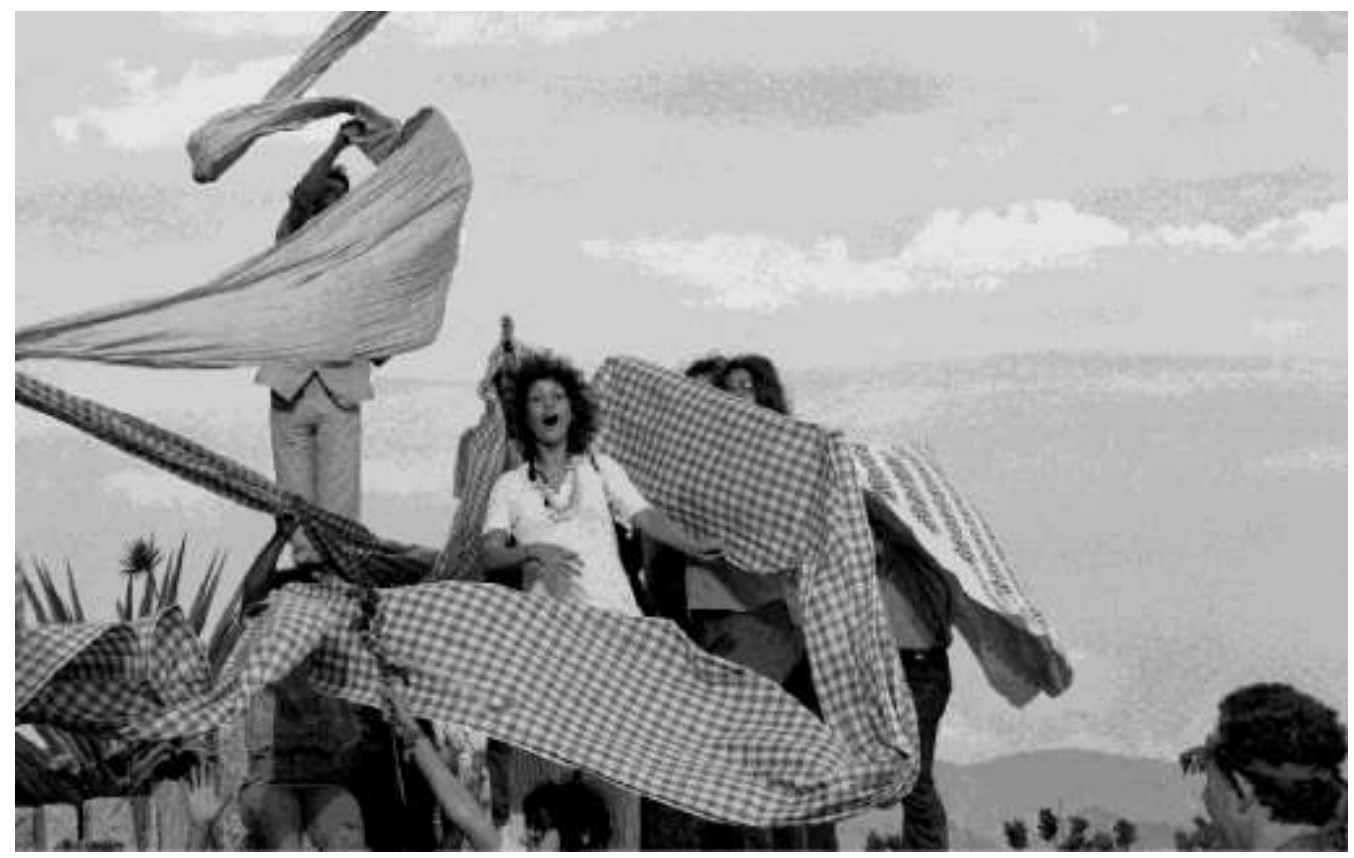

Fig. 2 - Raul Pedreira

O tecido do domingo, 1971.

fotografia

(Fonte: GOGAN, Jessica (Org.); MORAIS, Frederico. Domingos da Criação: uma coleção poética do experimental em arte e educação. Rio de Janeiro: Instituto MESA, 2017, p. 66) 
p. 25), à maneira que Morais entendia a liberação criativa presente nos Domingos da Criação ou em sua "futura cidade lúdica". A brincadeira e o jogo também fariam parte desse urbanismo e seriam um meio fundamental para libertar o cidadão comum das amarras que impedem uma vida verdadeiramente livre. Para os situacionistas, "sua arquitetura um dia revolucionaria a vida cotidiana e liberaria o cidadão comum em um mundo de experimento, anarquia e brincadeira". (SADLER, 1998, p. 69)

Morais, por sua vez, não chega a esboçar uma espacialidade dessa cidade, mas indica noções próximas às dos desvios - détournements - situacionistas de apropriação da estrutura da cidade construída em favor da experiência lúdica e afetiva dos usuários. Para Morais, "a cidade é a extensão natural do museu de arte. É na rua, onde o 'meio formal' é mais ativo, que ocorrem as experiências fundamentais do homem". (MORAIS in GOGAN, 2017, p. 270) O museu deveria, portanto, levar suas atividades museológicas para a rua, "integrando-se ao cotidiano e fazendo da cidade (a rua, o aterro, a praça ou parque, os veículos de comunicação de massa) sua extensão natural" (MORAIS in GOGAN, 2017, p. 270), caso contrário perderia pé de seu papel social.

Uma proposta que deve ser mencionada dentro da discussão situacionista é a Nova Babilônia do artista holandês Constant Nieuwenhuys. Nova Babilônia apresenta esboços de situações dessa futura cidade do urbanismo unitário, inspirada inicialmente em acampamentos ciganos. Segundo Guilherme Wisnik (2012, p. 129), a proposta de Constant Nieuwenhuys era a de "uma megaestrutura em escala planetária, uma cidade nômade e flexível que tenderia a ocupar toda a Terra", com níveis irregulares superpostos e "construída com elementos leves e desmontáveis", com estrutura metálica recoberta por materiais novos à época, como titânio e náilon. Ainda de acordo com Wisnik, isso indicaria "uma ideia de aglomeração e mobilidade, correspondendo a uma noção dinâmica da vida". Em relação à complexidade espacial, Nieuwenhuys afirma que, na Nova Babilônia é privilegiada "a desorientação que promove a aventura, o jogo, a mudança criadora. 0 espaço da Nova Babilônia tem todas as características de um espaço labiríntico onde os movimentos podem ocorrer sem impedimentos de ordem espacial ou temporal". (NIEUWENHUYS apud SADLER, 1998, p. 132)

Poiésis, Niterói, v. 20, n. 33, jan./jun. 2019. 
Para Nieuwenhuys essa proposta não era um projeto urbanístico e tampouco "uma obra de arte no sentido tradicional do termo [...]", mas sim "um jogo criativo com um ambiente imaginário". (NIEUWENHUYS apud SADLER, 1998, p. 123) Ou seja, novamente estamos diante de um verdadeiro Crelazer urbano, que se liga também à desmaterialização da obra de arte no período e na conversão do artista ou arquiteto como propositor de situações para que os usuários delas se apropriem. A substituição do produto artístico acabado pela atividade criativa também liga Morais e Nieuwenhuys, dentro de uma lógica de desalienação do público. Segundo Morais, "o espectador comum está alienado não só da arte (produto) mas da criação (processo)" no sistema museológico tradicional e seria necessário levar ao público não "a arte (produto acabado)", "mas a própria criação, ampliando-se, assim, a faixa de criadores de arte mais do que de consumidores de arte". (MORAIS in GOGAN, 2017, p. 242)

\section{Antecedentes na trajetória de Frederico Morais}

Ao abordar a gênese dos Domingos da Criação, Morais sempre se refere a eventos que os antecederam em sua atuação como crítico e curador. O primeiro deles foi a exposição Vanguarda Brasileira, realizada no edifício da reitoria da UFMG em 1966, ainda em construção à época. Segundo Morais, foi ali que ele se "descobriu" enquanto crítico e curador "propositor", tendo significado "um momento de inflexão" em sua atuação. (MORAIS, 2013, p. 338) O fato de a exposição ter acontecido em um edifício em construção já nos chama a atenção, dado que é uma proposta bastante inovadora até mesmo para os dias de hoje. A crítica e pesquisadora Michelle Sommer tem trabalhado ideias relativas ao que identifica como um "topos expográfico contemporâneo" e analisa algumas exposições e intervenções artísticas contemporâneas que trabalham dentro da lógica do que ela chama de "contraexposições", cuja gênese no Brasil podemos identificar em algumas das exposições e eventos promovidos por Morais. Tais exposições, como Museu do Homem Diagonal, da artista Renata Lucas, e Permanências e Destruições, organizada por João Paulo Quintella em espaços inusitados como uma ilha na baía de Guanabara e um 
edifício em construção abandonado na Barra da Tijuca, são exemplos dessa genealogia da qual Morais é um dos precursores.

\section{Na construção de outras gramáticas expositivas, a exposição deixa de ser exclusivamente o lugar final da apresentação pública de trabalhos de arte para ser facilitadora da continuidade na investigação de processos curatoriais e artísticos, em sobreposição. Criam-se situações para a integração entre arte e ar- quitetura em lugares espećficicos. (SOMMER, 2017, p. 1939)}

A seleção dos artistas da Vanguarda Brasileira, por sua vez, a maioria deles cariocas ou atuantes no Rio de Janeiro, nos dá a ver a situação da vanguarda no país naquele momento de maneira bastante próxima à que se daria na emblemática exposição Nova Objetividade Brasileira, realizada no MAM-RJ no ano seguinte. Isto porque ambas apresentaram um retrato do momento das vanguardas brasileiras em sua transição do neoconcretismo para as novas figurações e conceitualismos que emergiriam com mais força na década seguinte. Em relação à Nova Objetividade, Oiticica afirma, no texto de apresentação da exposição, que a reunião de artistas apresentava um "estado, [...] uma 'chegada', constituída de múltiplas tendências", cuja unidade seria dada pela ideia de 'nova objetividade'. Uma das principais características desse estado seria a expressão da "vontade construtiva geral" (OITICICA, 1986, p. 84), sem seguir postulados estritos que regulassem a prática de diversos artistas como nas vanguardas concretas da década anterior. No mesmo texto, Oiticica também cita a importância da atuação de Morais, que teria formulado a ideia de "uma 'arte dos sentidos', com a busca de estruturas básicas para o objeto" (OITICICA, 1986, p. 84), rompendo com as categorias tradicionais de escultura e pintura, algo que se radicalizaria nas ações que promoveu no Parque Municipal de Belo Horizonte em 1970.

A sintonia de Morais está conectada também com o contexto artístico mundial e, antes de voltarmos ao MAM-RJ, seguiremos em Belo Horizonte, onde, em 1970, Morais organizou simultaneamente dois eventos interligados: a manifestação Do corpo à terra, no Parque Municipal, e a exposição Objeto e participação, no Palácio das Artes. Ambos eventos fazem parte de proposições pioneiras em nível mundial, sobretudo a manifestação Do corpo

Poiésis, Niterói, v. 20, n. 33, jan./jun. 2019. 


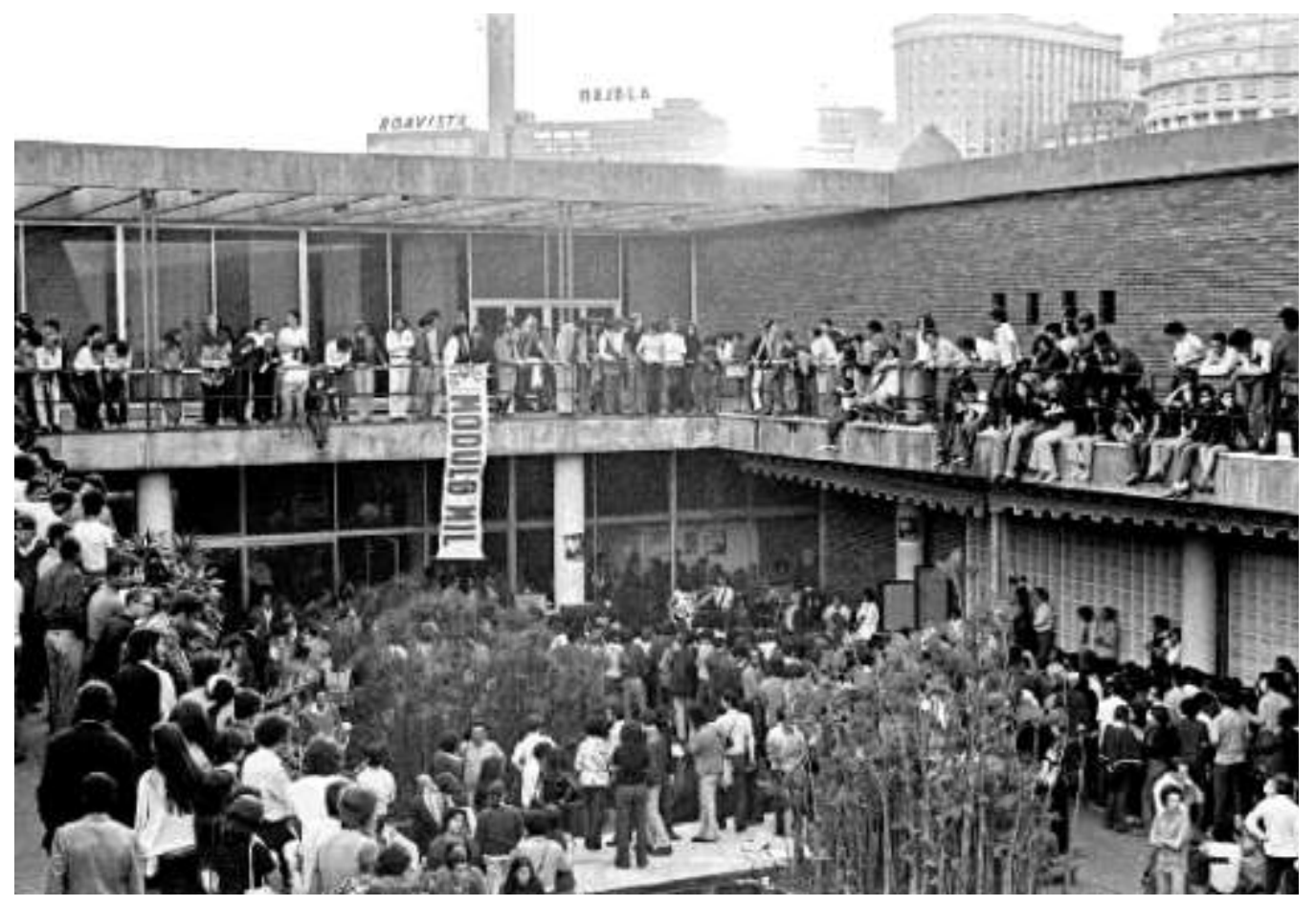

Fig. 3 - Beto Felício

O som do domingo, 1971.

fotografia

(Fonte: GOGAN, Jessica (Org.); MORAIS, Frederico. Domingos da Criação: uma coleção poética do

experimental em arte e educação. Rio de Janeiro: Instituto MESA, 2017, p. 102) 
à terra, na qual os artistas realizaram seus trabalhos com total liberdade em meio ao parque e sem que ninguém conseguisse ter acesso ao conjunto completo de obras. Da mêsma maneira,

os trabalhos realizados permaneceram em seus locais até sua destruição, acentuando o caráter efêmero e deliberadamente precário de boa parte da criação artística atual, que, tendo evoluído do objeto à ação, esgota-se no tempo de sua realização, passando a existir apenas como registro e/ou documento. (MORAIS, 2013, p. 349)

Dois eventos simultâneos, que se apropriam do espaço do parque do mesmo modo que o Aterro adentra o MAM-RJ, como afirma o próprio Morais (2013, p. 348): "duas instituições culturais localizadas em dois grandes parques públicos, estimulando-se mutuamente". Não entrarei aqui na descrição das ações e obras dos artistas participantes, mas cabe registrar que eles também formam parte de um retrato da geração artística da virada da década de 1960 para a de 1970, já incorporando tons mais diretamente conceituais e políticos, como no caso dos trabalhos de Cildo Meireles e Artur Barrio, por exemplo. Cabe ressaltar, porém, essa simbiose entre o objeto artístico e o ambiente natural no qual eles irão se dissolver e retornar à natureza, como é evidente nas trouxas ensanguentadas de Barrio, no Monumento Totem de Cildo, nos jardins de milho que Lotus Lobo tentou plantar em meio ao parque e na trilha de açúcar que o artista Lee Jaffe espalhou pela Serra do Curral sob as instruções de Hélio Oiticica, que não pode comparecer ao evento.

\section{Frederico Morais e o Rio de Janeiro}

Chegamos enfim ao Rio de Janeiro, para onde Frederico Morais se mudou logo depois da exposição Vanguarda Brasileira, para escrever no Diário de Notícias e dar aulas nos cursos de arte do MAM-RJ. Seu primeiro lance em direção à proposta de democratização da criatividade se deu com o evento Arte no Aterro: um mês de arte pública, realizado em julho de 1968. Mais um evento que Morais promoveu, não apenas para registrar um perfil da produção artística do momento, mas para de fato levar tais processos criativos para as

Poiésis, Niterói, v. 20, n. 33, jan./jun. 2019. 
massas, inclusive entregando volantes promocionais do evento em diversos locais públicos e até mesmo na porta de estádios de futebol da cidade.

Segundo Morais, "o evento abrangeu um conjunto de exposições de arte contemporânea, manifestações de arte de vanguarda, aulas e atividades criativas para crianças e adultos". (MORAIS in GOGAN, 2017, p. 236) Tratava-se, portanto, de um verdadeiro encontro entre proposições artísticas mais ou menos ligadas às produções individuais dos artistas lembrando que a vanguarda brasileira já tinha um caráter eminentemente participativo e propositor de ações - com atividades mais propriamente pedagógicas ou recreativas. No último domingo, as atividades foram lideradas por Hélio Oiticica e Rogério Duarte, promovendo a manifestação que chamaram de Apocalipopótese: "um conjunto de obrasevento acionado por Lygia Pape (Sementes), Antonio Manuel (Urnas quentes) e Roberto Lanari". (MORAIS in GOGAN, 2017, p. 236)

Um evento unindo a vanguarda e a pedagogia, que iria reverberar nos Domingos da Criação alguns anos depois, colocando em prática postulados de Oiticica oriundos de sua própria produção e às intenções éticas que buscava dar a ela. Segundo Roberto Schwarz, "o gesto didático [...] vibrava como exemplo, valorizava o que à cultura confinada não era permitido: o contato político com o povo" (SCHWARZ in GOGAN, 2017, p. 254), lembrando que em tempos de AI-5 qualquer reunião com mais de cinco pessoas já era considerado um ato subversivo.

Oiticica também aborda este tema ao falar que Apocalipopótese era um "contato grupal coletivo: não imposição de uma 'ideia estética grupal', mas a experiência do grupo aberto num contato coletivo direto" (OITICICA, 1986, p. 128), reverberando as ideias de Morais quanto à participação criativa de grupos os mais diversos possíveis e não previamente estruturados. O encontro entre arte e política, portanto, era inevitável em um momento sombrio do país, no qual as opiniões deveriam ser caladas para não levar aos calabouços da ditadura militar e à inevitável tortura. Era também um momento de encontro no qual os afetos poderiam, pelo menos por algumas horas, ser mobilizados sem que fossem alvo de repressão da polícia. Como afirma ainda Oiticica a respeito de Apocalipopótese, a in- 
terferência direta do 'imponderável' tinha que ser admitida em uma experiência deste porte.

\section{A desconhecida "participação coletiva" - como nas marchas de protesto (aliás, creio eu, a grande passeata dos cem mil teria sido a introdução para a Apocalipopótese: sua impressão e vivências gerais ainda me são presentes) - mas aqui, nessa manifestação, as surpresas do desconhecido foram eficazes - sempre o são e sempre "falta algo" em todas elas, o que é importante e bom. (0ITICICA, 1986, p. 128- 129)}

Ou seja, como na "explosão de criatividade política" de maio de 1968, a política institucional e a política dos afetos se encontram e se retroalimentam de diversas maneiras. 0 próprio Frederico Morais também afirma que Apocalipopótese foi "premonitório", já que no dia seguinte à sua realização, "a polícia empregaria jatos de água colorida e cães na perseguição aos manifestantes de mais uma passeata no centro do Rio de Janeiro contra a ditadura militar" (2013, p. 342), evocando a ação de Rogério Duarte que levou um adestrador de cães para o Aterro. Para Morais, o encontro entre arte e política é inevitável quando a primeira é levada à rua. Não seria preciso, portanto, se produzir uma arte política no sentido estrito do termo, mas apenas a mobilização afetiva promovida por tais eventos já expunha e libertava os participantes de uma série de repressões que atravessavam o cotidiano da época.

Outro precedente na trajetória de Morais deve ser mencionado antes de chegarmos aos Domingos da Criação. Em 1969, Morais passou a coordenar o núcleo de cursos do MAM$\mathrm{RJ}$, promovendo uma ampla reforma no currículo, que integrou os ateliês, antes separados pelas técnicas artísticas tradicionais (pintura, gravura, escultura), entre si e com as aulas de história e teoria da arte. (MORAIS, 2013, p. 338) Mais uma vez, vemos Morais atento ao desenvolvimento da produção artística contemporânea que, superadas as divisões em "-ismos" das vanguardas e das querelas em relação à especificidade dos meios promovida por Clement Greenberg em relação à produção do alto modernismo, misturava todas as técnicas de acordo com as necessidades específicas da proposição artística. Assim, excluíam-se "todas as formas didáticas tradicionais" e não se pretendia "'formar

Poiésis, Niterói, v. 20, n. 33, jan./jun. 2019. 
ou transformar pessoas em artistas', mas acordá-las para a linguagem mais universal de comunicação humana: a arte". (MORAIS in GOGAN, 2017, p. 283) Essa dissolução dos meios artísticos também é indicada por Morais em relação à pedagogia a ser implementada na formação prevista nos cursos do MAM-RJ:

\section{a noção de ateliê (sala de aula) se amplia, passando a ser qualquer lugar da cidade onde estiverem reunidos alunos e professores. Se o lugar escolhido como ateliê for, por exemplo, uma praia, o material a ser trabalhado será a areia, a água, o vento etc., e a técnica a ser desenvolvida, aquela adequada aos materiais disponíveis no momento ou às propostas a serem desenvolvidas. (GOGAN, 2017, p. 240)}

Mais uma vez comparece uma noção fluida da relação do MAM-RJ com o Aterro, algo que Anna Bella Geiger também corrobora, quando fala que depois de voltar ao Brasil em 1970, encontra no MAM-RJ um espaço para atuar de maneira "experimental nos cursos livres". Levando "os alunos para fora da sala de aula, mais especificamente para a área externa do MAM e daí para a costa marítima do Aterro, ainda em obra". (in GOGAN, 2017, p. 192)

\section{Os Domingos da Criação}

Chegamos enfim aos Domingos da Criação, um dos pontos altos da prática pedagógica experimental de Morais e de sua intenção de transformar o lazer em algo criativo que reverberasse na vida cotidiana dos participantes, ou seja, colocar em prática o Crelazer que Hélio Oiticica vislumbrou. Segundo Gogan, "Frederico viu os Domingos como uma oportunidade para nivelar uma crítica marxista da noção burguesa de entretenimento dominical e reconfigurar o lazer, e não a atividade, com base na noção de Oiticica de uma experiência criativa ativa e aberta de 'crelazer'". (GOGAN, 2017, p. 256) De todo modo, apesar de certo metodismo de Frederico Morais, os eventos dos domingos foram bastante anárquicos em sua busca por liberar a criatividade intrínseca de todos. As bases teóricas e práticas para a elaboração das atividades dos domingos foram as que esboçamos até aqui, como se se tratasse de um processo linear e progressivo em direção à efetivação de 
suas ideias em uma grande síntese criativa, algo que, no entanto, só pode ser captado a posteriori.

Os Domingos da Criação foram "manifestações de livre criatividade com novos materiais, idealizados e coordenados [por Frederico Morais], realizados na área externa do MAM entre janeiro e agosto de 1971". (MORAIS in GOGAN, 2017, p. 239) Morais organizou seis eventos com diferentes materiais norteando as atividades: Um domingo de papel (24 de janeiro), 0 domingo por um fio (7 de março), $O$ tecido de domingo (28 de março), Domingo terra a terra (25 de abril), O som do domingo (30 de maio) e $O$ corpo a corpo do domingo (29 de agosto). A ideia partiu da vontade de Morais em oferecer atividades para os frequentadores do MAM-RJ e de seus cursos ao longo dos meses de férias de janeiro e fevereiro, quando as atividades artísticas na cidade diminuíam consideravelmente. Partindo da experiência da Arte no Aterro, Morais organizou algo ainda mais independente das propostas dos artistas; quem ditava as atividades nos Domingos eram os próprios materiais e não algum artista, nem mesmo no papel de propositor.

A visão de Morais em relação ao uso dos materiais também é importante de ser destacada e vai na linha da integração das técnicas artísticas mencionada anteriormente. Para Morais (in GOGAN, 2017, p. 242), "todo e qualquer material [...] pode ser tratado esteticamente" e o uso de "materiais precários adquire importância e significado especialmente em países em desenvolvimento ou emergente como o Brasil. É a 'estética da fome' de Glauber Rocha". Mais uma vez vemos como Morais estava engajado em uma verdadeira revolução comportamental que passava diretamente pela relação entre ética e estética, de modo que estivesse afinada com as condições políticas e sociais de um país 'em desenvolvimento' e sob a repressão de um regime militar, como o Brasil do período.

As repercussões dos Domingos nas páginas de jornal demonstram que os eventos de Morais de fato tiveram um alcance urbano que incluía os meios de comunicação de massa. Também os relatos registrados à época confirmam a intenção do organizador em reformular a relação entre lazer e trabalho dentro da sociedade capitalista, como afirma uma participante: "se todos se decidissem por este tipo de participação coletiva e liberassem

Poiésis, Niterói, v. 20, n. 33, jan./jun. 2019. 

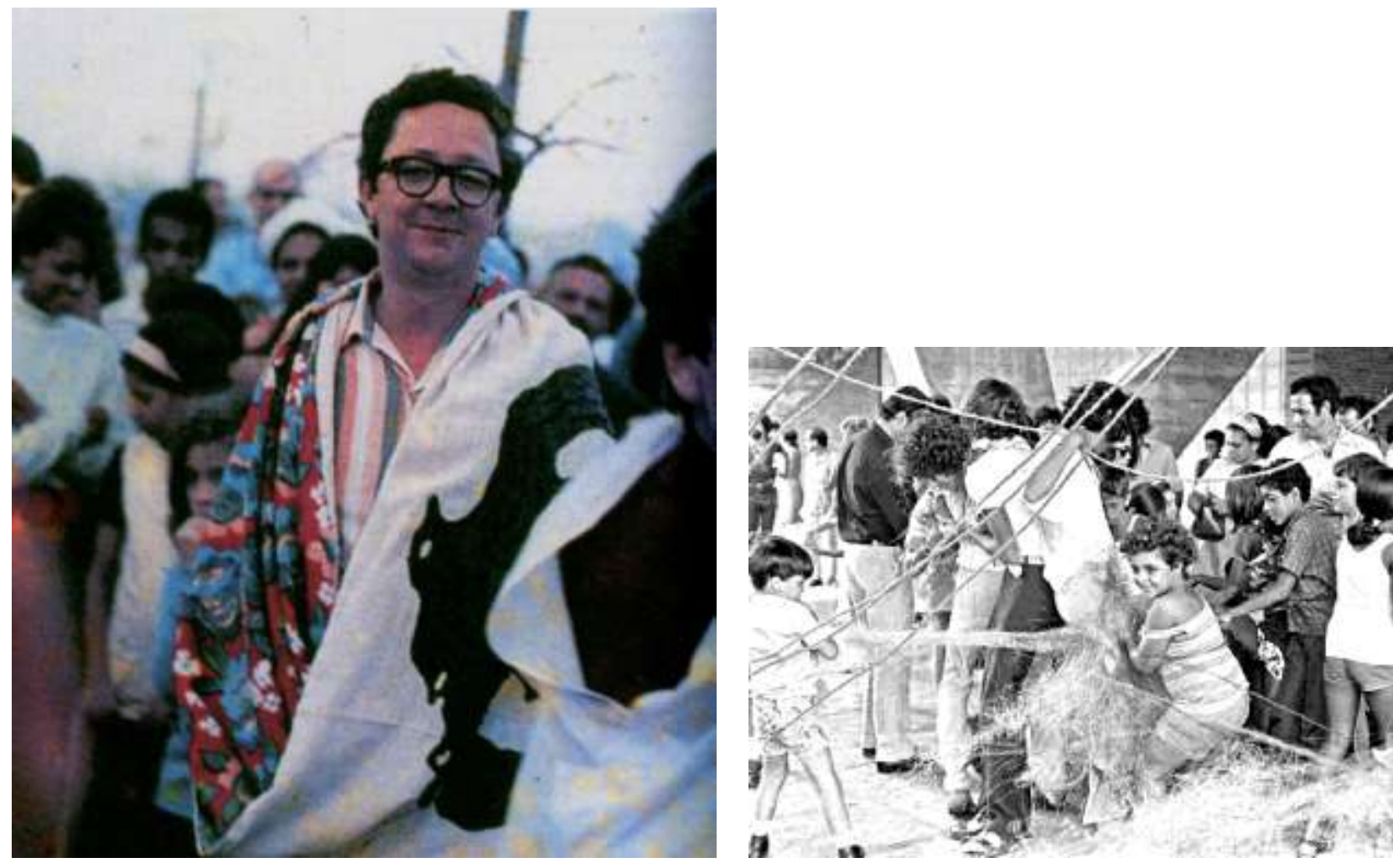

Fig. 4 - Frederico Morais vestindo Parangolé Guevarcália, durante o evento Apocalipopótese, no Aterro do Flamengo, 1968 (á esquerda).

(Fonte: MORAIS, Frederico. A arte não pertence a ninguém [entrevista]. Revista UFMG, Belo Horizonte, v. 20, n. 1, jan./jun. 2013, p. 336)

Fig. 5 - Beto Felício

O domingo por um fio, 1971. fotografia

(Fonte: GOGAN, Jessica (Org.).; MORAIS, Frederico. Domingos da criação: uma coleção poética do experimental em arte e educação. Rio de Janeiro: Instituto MESA, 2017, p. 32) 
sua criatividade, poderíamos dispensar os psicanalistas". O relato da costureira Jelza Garcia também demonstra essa noção das atividades dos Domingos: "tenho costurado toda minha vida e nunca pensei que pudesse me divertir tanto como aqui". (MORAIS in GO-GAN, 2017, p. 243-244)

Assim, mesmo que por algumas horas, os participantes se apropriavam daqueles materiais que Ihes eram familiares para subverter suas funções utilitárias e mesmo uma costureira pode se divertir a partir de seu próprio metier, praticado ali de forma lúdica. Talvez por isso um dos domingos que seriam organizados na sequência abordasse profissões populares, para trazer a criatividade também para o trabalho, dando mais uma volta na mistura entre lazer, trabalho e criatividade que Morais buscava disseminar no mundo. O crítico também indica que essa "criatividade de base", da qual nos fala Roberto Pontual (in GOGAN, 2017, p. 293), estava ligada à ideia de uma produção de si, tema caro à filosofia francesa da década de 1970, demonstrando outro sinal que a antena de Morais captou:

\section{a noção de criatividade está ligada à recuperação que o homem faz de si mesmo no sentido de alcançar a plenitude de seu ser. A produção de si mesmo, entretanto é um processo aberto no qual o homem se manifesta contínua e livremente. [...] Só quem está permanentemente aberto à busca do novo e do original, quem cria todo o tempo pode enfrentar a massificação e o caráter repressivo da sociedade atual, a massagem contínua que representa a mensagem publicitária. (MORAIS in GOGAN, 2017, p. 280)}

Novamente comparecem menções à ideia da sujeição à imagem midiática e publicitária que nos é imposta pela "sociedade do espetáculo" e para a qual Morais via os Domingos como um possível "antídoto", ajudando a formar "uma nova imagem da sociedade que está surgindo. É a imagem-ação como define Alfred Willener: a imagin/ação". (MORAIS in GOGAN, 2017, p. 279-280).

Os Domingos acabaram sendo suspensos por uma nova direção que assumiu o MAM-RJ, mas deixaram seus frutos tanto em cursos do museu, que levaram adiante algumas propostas de utilização de materiais como papel, ou em iniciativas disseminadas pelo Brasil e pelo mundo em práticas de arte-educação, que escapam ao tradicional formato de "brin-

Poiésis, Niterói, v. 20, n. 33, jan./jun. 2019. 
cadeira com sucatas". Mas, como nos lembra Oiticica (1974), se "o experimental pode retomar nunca reviver", a força dos domingos acabou se esvaindo em meio à repressão da ditadura militar e, depois do grande incêndio do MAM-RJ, em 1978, o experimental saiu de vez da cena artística instituída - seja pela sua institucionalização definitiva, seja por sua expulsão de fato dos circuitos artísticos mais tradicionais. Falar dos Domingos nos tempos sombrios da contemporaneidade tupiniquim, com seus futuros prometidos sempre interrompidos, é falar de uma prática que, se não pode ser repetida como tal, ao menos indica possibilidades de confronto por meio dos afetos. Não é à toa que propostas radicais como os eventos de Frederico Morais, ou mesmo as produções de Hélio Oiticica e Lygia Clark, tenham ficado no ostracismo por tantos anos e quando são recuperadas o são em seus aspectos mais facilmente catalogáveis dentro dos cânones da história da arte, de preferência europeia. Assim, devemos tirá-los das subterrânias às quais foram relegadas e libertar a potência experimental antropofágica que late dentro de cada um de nós, se quisermos ter um futuro menos sombrio do que o que se avizinha. Vimos aqui experimentos que colocaram em prática utopias que pareciam irrealizáveis; temos agora que procurar nossas próprias.

\section{Notas}

\footnotetext{
${ }^{1}$ Niomar Moniz Sodré foi Presidente/Diretora do Museu de Arte Moderna do Rio de Janeiro entre 1951 e 1961.
} 


\section{Referências}

BRAGA, Paula. Hélio Oiticica: singularidade, multiplicidade. São Paulo: Perspectiva / Fapesp, 2013.

FAVARETTO, Celso Fernando. A invenção de Hélio Oiticica. São Paulo: EDUSP, 1992.

GOGAN, Jessica (Org.); MORAIS, Frederico. Domingos da Criação: uma coleção poética do experimental em arte e educação. Rio de Janeiro: Instituto MESA, 2017.

JAMESON, Fredric. The Aesthetics of Singularity. New Left Review, 92, p. 101-132, mar./abr. 2015.

MORAIS, Frederico. Artes plásticas: a crise da hora atual. Rio de Janeiro: Paz e Terra, 1975.

MORAIS, Frederico. Do corpo à terra. In FERREIRA, Glória (Org.). Crítica de arte no Brasil: temáticas contemporâneas. Rio de Janeiro: Funarte, 2006. p. 195-200.

MORAIS, Frederico. A arte não pertence a ninguém [entrevista]. Revista UFMG, Belo Horizonte, v. 20, n.1, p. 336-351, jan./jun. 2013.

OITICICA, Hélio. Aspiro ao grande labirinto. Rio de Janeiro: Rocco, 1986.

OITICICA, Hélio. Experimentar o experimental. Publicado originalmente na Revista Navilouca, 1974. Disponível em http://54.232.114.233/extranet/enciclopedia/ho/index. $\mathrm{cfm}$ ?fuseaction $=$ documentos $\&$ cod $=362 \&$ tipo $=2$. Acesso em abril de 2019 .

ROCHA, Paulo Mendes da. A cidade enquanto liberdade [entrevista]. GFAU. Corredor das Humanas: a poesia que poderia ter sido e que não foi. São Paulo: GFAU, 2009, p. 20-27

SADLER, Simon. The Situationist City. Cambridge: MIT Press. 1998.

SOMMER, Michelle Farias. Contraexposição, um estado expositivo contemporâneo. Anais do $26^{\circ}$ Encontro da ANPAP. Campinas: Pontifícia Universidade Católica de Campinas, 2017, p. 1936-1950.

WISNIK, Guilherme. Dentro do nevoeiro: diálogos cruzados entre arte e arquitetura. Tese de doutorado, Faculdade de Arquitetura e Urbanismo, Universidade de São Paulo, 2012.

Poiésis, Niterói, v. 20, n. 33, jan./jun. 2019. 